\title{
THERMAL CHEMISTRY OF ICE MIXTURES OF ASTROPHYSICAL RELEVANCE
}

\author{
W.A. Schutte \\ Leiden Observatory Laboratory, P.O. Box 9513, 2300 RA Leiden, \\ The Netherlands
}

\begin{abstract}
Two different types of cryogenic thermal reactions have been indicated in astrophysical ice analogs. First, a very low activation barrier allows reactions between acids and bases and the formation of ions. Second, in the presence of traces of $\mathrm{NH}_{3}$, formaldehyde polymerizes at temperatures in excess of $\sim 60 \mathrm{~K}$. The possible relevance of cryogenic thermal reactions in forming cometary matter is discussed.

O1997 COSPAR. Published by Elsevier Science Ltd.
\end{abstract}

\section{INTRODUCTION}

The field of thermal chemistry under cryogenic conditions, certainly with regard to the study of interstellar ice analogs, is fairly new. To start this review, it is necessary to make a definition of the type of reactions we want to designate as such. The following definition underlies the review which is here presented; Cryogenic thermal chemistry encompasses reactions which proceed under high vacuum conditions in solid samples of volatile molecules and which are either purely thermally induced, or induced by UV irradiation, providing that the reaction scheme does not involve photocleavage of molecular bonds. Of course this latter restriction separates thermal chemistry from true photo-chemistry. An example of the latter would be the formation of radicals by photocleavage of molecular bonds and subsequent formation of new species by reactions between the radicals (e.g., Agarwal et al. 1985). On the other hand, this definition does encompass for example polymerization of solid formaldehyde upon UV irradiation (Goldanskii et al. 1973). One could perhaps argue that the latter type of thermal chemistry is not "the real thing", since UV photon absorption will create local "hot-spots" in the ice in which the kinetic energy well exceeds the cryogenic condition. For example, a $0.2 \mathrm{eV} \mathrm{OH}$ fragment of the photocleavage of $\mathrm{H}_{2} \mathrm{O}$ could raise the kinetic energy level of a volume of $\sim 10$ molecules by the equivalent of a temperature rise of the order of a few hundred degrees, and thus could enable reactions which otherwise occur at room temperature under atmospheric pressure. However, as will be reviewed below, both types of thermal chemistry generally involve very identical reactants, and show great similarity in the products. Therefore, a discussion of the radiationless thermal chemistry without including the radiation-induced reactions would be of limited value with regard to interpreting the composition of astrophysical solids. 
According to the above definition, two types of thermal chemistry in astrophysical ice analogs have been reported. The first type involves the production of ions by acid-base reactions in astrophysical ice analogs (Grim and Greenberg 1987, Grim et al. 1989). Second, it was observed that formaldehyde polymerization can occur during moderate warm-up ( $\geq \sim 60 \mathrm{~K}$ ) in mixtures of $\mathrm{H}_{2} \mathrm{CO}, \mathrm{H}_{2} \mathrm{O}$ and $\mathrm{CH}_{3} \mathrm{OH}$ in the presence of, at least, a trace amount of $\mathrm{NH}_{3}$ (Schutte et al. 1993). In a subsequent study, Bernstein et al. (1995) and Gerakines et al. (1996) showed that a variety of $\mathrm{H}_{2} \mathrm{CO}$ polymers are produced by $\mathrm{UV}$ photolysis as well.

This paper is laid out as follows. In the first section the acid-base chemistry of astrophysical ice analogs is reviewed. Subsequently, we discuss formaldehyde polymerization under cryogenic conditions. Finally, we discuss which role cryogenic thermal reactions may play in interstellar chemistry and in the formation of cometary matter.

\section{ACID-BASE REACTIONS}

In the physical-chemical literature acid-base reactions under cryogenic conditions were first reported for the $\mathrm{HNO}_{3} / \mathrm{NH}_{3}$ system (Ritzhaupt and Devlin 1977). Acid-base reactions and ion formation in astrophysical ice analogs were described by Grim and Greenberg (1987) and Grim et al. (1989). A number of infrared features produced by irradiation of astrophysical ice analogs $\left(\mathrm{H}_{2} \mathrm{O}, \mathrm{CO}, \mathrm{NH}_{3}, \mathrm{O}_{2}\right)$ were assigned to charged species such as $\mathrm{NH}_{4}^{+}, \mathrm{OCN}^{-}, \mathrm{HCOO}^{-}, \mathrm{NO}_{2}^{-}$, and $\mathrm{NO}_{3}^{-}$. While the base $\mathrm{NH}_{3}$ was included in the initial deposition, the acids corresponding to the negative ions were produced during the UV photolysis, e.g.,

$\mathrm{NH}_{3}+\mathrm{h} \nu \rightarrow \mathrm{NH}+\mathrm{H}_{2}$

$\mathrm{NH}+\mathrm{CO} \rightarrow \mathrm{HNCO}$

Generally these experiments were performed with ubiquitous $\mathrm{NH}_{3}$, and at the relatively high energy density obtained after UV photon absorption, the bulk of the produced acids were converted to their corresponding ions.

Besides under irradiation, acid-base reaction can also be induced purely thermal. This is illustrated in Figure 1, which displays the thermal evolution of the sample $\mathrm{H}_{2} \mathrm{O} / \mathrm{NH}_{3} / \mathrm{HCOOH}=$ 100/22/5 (From Schutte \& Greenberg 1996). Besides the features due to the deposited species at $1640 \mathrm{~cm}^{-1}\left(\mathrm{H}_{2} \mathrm{O}\right.$; d'Hendecourt and Allamandola 1986), $1120 \mathrm{~cm}^{-1}\left(\mathrm{NH}_{3}\right.$; d'Hendecourt and Allamandola 1986), $1710 \mathrm{~cm}^{-1}$ and $1230 \mathrm{~cm}^{-1}$ (due to the $\nu_{C}=O$ and $\nu_{C-O}$ modes of $\mathrm{HCOOH}$; cf. spectrum (a) of Figure 1 showing pure solid $\mathrm{HCOOH}$ ), features appear at 1580, 1500, 1380 and $1350 \mathrm{~cm}^{-1}$ (The $1380 \mathrm{~cm}^{-1}$ of $\mathrm{HCOO}^{-}$is not to be confused with the weak $\mathrm{O}-\mathrm{H}$ bending mode of $\mathrm{HCOOH}$ near this position displayed in spectrum (a), whose contribution in the mixed ice is negligible). The 1580,1380 and $1350 \mathrm{~cm}^{-1}$ features coincide within a few $\mathrm{cm}^{-1}$ with the $\nu_{4}, \nu_{5}$, and $\nu_{2}$ features of $\mathrm{HCOO}^{-}$in aqueous solution (Ito and Bernstein 1956), while the 1500 $\mathrm{cm}^{-1}$ falls close to the value reported for the $\nu_{2}$ mode of the $\mathrm{NH}_{4}^{+}$ion in solid argon (Ritzhaupt and Devlin 1977). During the warm-up these bands increase, while the HCOOH bands decrease. It is unlikely that the increase of these features is due to a modification of the matrix, since their positions, widths and relative intensities do not change. It thus appears that proton transfer takes 
place during the warm-up of the ice, consistent with the disappearance of the $\mathrm{HCOOH}$ features (Figure 1). The acid-base reaction scheme requires a simultaneous decrease by $\sim 15 \%$ for the $1120 \mathrm{~cm}^{-1}$ band of the $\mathrm{NH}_{3}$ umbrella mode. A careful analysis of the difference between the $10 \mathrm{~K}$ and $140 \mathrm{~K}$ spectra in Figure 1 indicates that this slight drop in band area indeed occurs, although a precise analysis is hindered by the uncertainty in the exact location of the baseline.

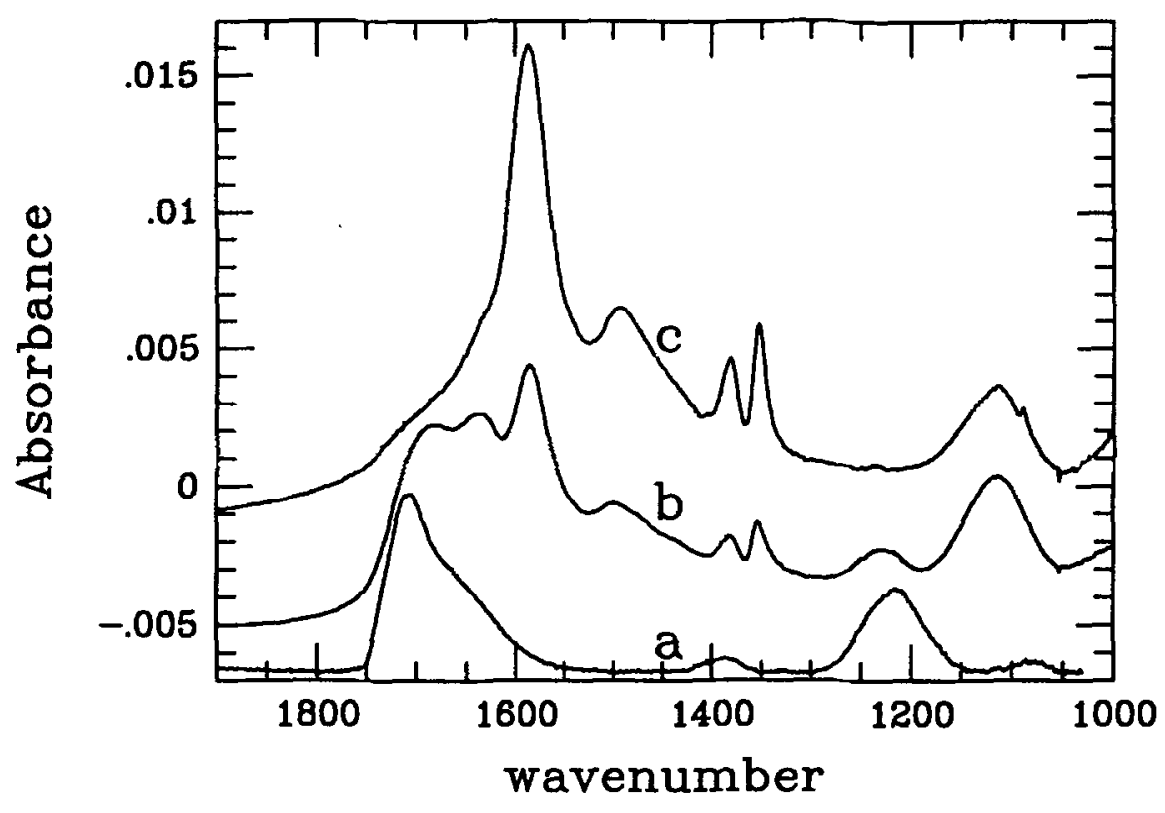

Fig. 1. Infrared spectra of: Pure solid $\mathrm{HCOOH}$ after deposition at $10 \mathrm{~K}(\mathrm{a}) ; \mathrm{H}_{2} \mathrm{O}: \mathrm{NH}_{3}: \mathrm{HCOOH}$ $=100: 22: 5$ after deposition at $10 \mathrm{~K}(\mathrm{~b})$, and after warm-up to $140 \mathrm{~K}$ (c; plotted at the same scale as b).

Reactions barriers for acid-base proton transfer appear to be very low, at least for the $\mathrm{NH}_{3} /$ $\mathrm{HCOOH}$ interaction illustrated in Figure 1. In this experiment a clear increase of the $\mathrm{HCOO}^{-}$ and $\mathrm{NH}_{4}^{+}$features is already observed upon warm-up from 10 to $30 \mathrm{~K}$. While the ions are already present directly after the deposition, this initial formation could be stimulated by the energy released during condensation as well as by the energy carried by the gas which, before depasition, is close to room temperature. The low abundance of the acid precursors relative to their ionic products in the UV photolysed samples of Grim et al. (1989) shows that any possible reaction barriers are easily overcome by the energy delivered by the photons. 


\section{FORMALDEHYDE POLYMERIZATION REACTIONS}

In ice samples, formaldehyde polymerization can be induced purely thermal or by UV photolysis. In the former case it was found that polymerization only occurs in the presence of at least a trace of $\mathrm{NH}_{3}(\sim 0.5 \%$; Schutte et al. 1993). While under UV photolysis polymerization readily occurs in a sample of pure $\mathrm{H}_{2} \mathrm{CO}$ ice, such reactions are inhibited or at least severely reduced in more diluted ice mixtures without $\mathrm{NH}_{3}$. Specifically, mixtures in which the $\mathrm{H}_{2} \mathrm{CO}$ is produced by photolysis of $\mathrm{CH}_{3} \mathrm{OH}$ show only limited polymerization, unless $\mathrm{NH}_{3}$ is included (Bernstein et al. 1995, Gerakines et al. 1996).

The products of formaldehyde polymerization reactions are very diverse and depend on the way of induction (thermal or UV) as well as the ice composition. Table 1 lists the polymerization products for the different experiments that have been described.

Table 1. Products of Formaldehyde Polymerization Reactions in Astrophysical Ice Analogs

\begin{tabular}{|c|c|c|c|}
\hline Induction & Mixture composition & Products & Ref. \\
\hline \multirow{7}{*}{$\begin{array}{l}\text { Thermal } \\
(\mathrm{T}>\sim 60 \mathrm{~K})\end{array}$} & Pure $\mathrm{H}_{2} \mathrm{CO}$ & No polymers observed & 1 \\
\hline & $\mathrm{H}_{2} \mathrm{O} / \mathrm{H}_{2} \mathrm{CO} / \mathrm{NH}_{3}$ & $\mathrm{HCO}\left[-\mathrm{O}-\mathrm{CH}_{2}\right]_{\mathfrak{n}}-\mathrm{H}$ & \\
\hline & & $\mathrm{HOCH}_{2} \mathrm{NH}_{2}$ & \\
\hline & & $\mathrm{HOCH}_{2}-\mathrm{O}-\mathrm{CH}_{2} \mathrm{NH}_{2}$ & \\
\hline & & $\mathrm{HOCH}_{2} \mathrm{OH}$ & \\
\hline & & $\mathrm{HOCH}_{2}-\mathrm{O}-\mathrm{CH}_{2} \mathrm{OH}$ & \\
\hline & $\mathrm{H}_{2} \mathrm{CO} / \mathrm{NH}_{3} / \mathrm{H}_{2} \mathrm{O} / \mathrm{CH}_{3} \mathrm{OH}$ & $\mathrm{H}_{3} \mathrm{C}-\mathrm{CH}(\mathrm{OH})-\mathrm{O}-\left(\mathrm{CH}_{3}\right)$ & 1 \\
\hline \multirow[t]{9}{*}{ UV } & Pure $\mathrm{H}_{2} \mathrm{CO}$ & $\mathrm{HCO}\left[-\mathrm{O}-\mathrm{CH}_{2}\right]_{\mathrm{n}}-\mathrm{H}$ & 2 \\
\hline & & $\mathrm{HCO}[-\mathrm{CH}(\mathrm{OH})]_{n}-\mathrm{CH}_{2}-\mathrm{OH}$ & 2 \\
\hline & Pure $\mathrm{CH}_{3} \mathrm{OH}^{\mathrm{a}}$ & $\mathrm{HCO}-\mathrm{O}-\mathrm{CH}_{3}$ & 2 \\
\hline & $\mathrm{H}_{2} \mathrm{O} / \mathrm{CH}_{3} \mathrm{OH} / \mathrm{NH}_{3}^{\mathrm{a}}$ & $\mathrm{C}_{6} \mathrm{H}_{12} \mathrm{~N}_{4}^{\mathrm{b}}$ & 3 \\
\hline & $\mathrm{H}_{2} \mathrm{O} / \mathrm{CH}_{3} \mathrm{OH}^{\mathrm{a}}$ & No polymers observed & 3 \\
\hline & $\mathrm{H}_{2} \mathrm{O} / \mathrm{CO} / \mathrm{NH}_{3}^{\mathrm{c}}$ & $\mathrm{HOCH}_{2}-\mathrm{CONH}_{2}$ & $4,5,6$ \\
\hline & & $\mathrm{CH}_{2}(\mathrm{OH})-\mathrm{COOH}$ & $4,5,6$ \\
\hline & & $\mathrm{HOCH}_{2}-\mathrm{CH}(\mathrm{OH})-\mathrm{CONH}_{2}$ & $4,5,6$ \\
\hline & & $\mathrm{HOCH}_{2}-\mathrm{CH}(\mathrm{OH})-\mathrm{COOH}$ & $4,5,6$ \\
\hline
\end{tabular}

1. Schutte et al. 1993; 2. Gerakines et al. 1996; 3. Bernstein et al. 1995; 4. Agarwal et al. 1985;

5. Briggs et al. 1992; 6. Schutte 1988.

${ }^{2}$ Formaldehyde produced by UV dissociation of $\mathrm{CH}_{3} \mathrm{OH}$.

${ }^{b}$ Hexamethylene Tetramine.

c Formaldehyde produced by $\mathrm{H}$ addition (from $\mathrm{H}_{2} \mathrm{O}$ or $\mathrm{NH}_{3}$ photodissociation) to $\mathrm{CO}$. 
The products which are obtained for various samples upon UV radiation are very similar to reaction products obtained from $\mathrm{H}_{2} \mathrm{CO}$ gas or aqueous solutions at room temperature (e.g., Walker 1964). This can be qualitatively understood by considering that the conditions prevalent in the "hot-spots" which are created in the ice by UV photon absorptions bear some similarity to room temperature conditions (see above). In this case reaction barricrs are relatively unimportant, and the chemistry will tend to produce the most stable species. Most notably among these is the complex molecule Hexamethylene Tetramine $\left(\mathrm{C}_{6} \mathrm{H}_{12} \mathrm{~N}_{4}\right)$, which is formed by irradiation of $\mathrm{H}_{2} \mathrm{O} / \mathrm{CH}_{3} \mathrm{OH} / \mathrm{NH}_{3}$ at $10 \mathrm{~K}$ (Bernstein et al. 1995). The $\mathrm{H}_{2} \mathrm{CO}$ is efficiently produced by UV dissociation of the $\mathrm{CH}_{3} \mathrm{OH}$ (Gerakines et al. 1996). At room temperature, hexamethylene tetramine is readily formed in an aqueous solution of $\mathrm{H}_{2} \mathrm{CO}$ with $\mathrm{NH}_{3}$.

On the other hand, the products formed by thermally induced polymerization of formaldehyde (Table 1) are not seen under room temperature conditions, or perhaps only as very short lived transients. Clearly, under these circumstances the limiting condition is the presence of an activation barrier rather than the stability of the end-products. A salient aspect of these type of reactions is that the chemistry is quite complex, i.e., besides $\mathrm{H}_{2} \mathrm{CO}$ a number of other ice constituents actively take part in the reactions (Table 1 ). The onset of polymerization occurs at $60 \mathrm{~K}$, indicating the existence of a small, but finite, activation barrier.

\section{CRYOGENIC THERMAL CHEMISTRY AND ASTROPHYSICS}

A large number of acids and bases consist of simple cumbinations of the abundant elements $\mathrm{H}, \mathrm{C}$, $\mathrm{O}$, and $\mathrm{N}$ which could possibly be produced on the surface of interstellar grains. Indeed species like the bases $\mathrm{NH}_{3}, \mathrm{~N}_{2} \mathrm{H}_{4}$ and the acids $\mathrm{HCOOH}, \mathrm{HNCO}$ and $\mathrm{HNO}$ are predicted by models of such processes (Tielens and Hagen 1982, Hasegawa et al. 1992, 1993). Furthermore, processing by UV may also produce acids (Grim et al. 1989). The reaction barrier for cryogenic acid-base reactions is so small that the heat of condensation could already be sufficient for some proton exchange to occur (see above). Also, if grain surface reactions are responsible for the acid or base production excess energy will be released. Finally, energy may be supplied by UV or energetic particles, especially near young stellar objects (e.g., Spaans et al. 1995). Thus, the production of ions in interstellar ice may proceed quite efficiently. Indeed, it was proposed that a ubiquitously observed interstellar solid state absorption band at $4.62 \mu \mathrm{m}$ may be due to the $\mathrm{OCN}^{-}$ion, based on an excellent match with the $\nu_{3}$ feature of this species in an interstellar ice analog (Grim and Greenberg 1987). Additional infrared bands of charged species which could be searched are a.o. the strong $\mathrm{HCOO}^{-}$feature near $1580 \mathrm{~cm}^{-1}$ and a broad feature around $1500 \mathrm{~cm}^{-1}$ of $\mathrm{NH}_{4}^{+}$(Figure 1). The spectroscopic data which are being now obtained by the Infrared Space Observatory (ISO) may thus be able to provide a better insight into the importance of cryogenic acid-base reactions in interstellar ices.

Aithough the initial comet ice may be directly supplied by interstellar grains (Greenberg 1982), the ices observed near the surface of a comet near perihelion as well as in the coma have been subjected to thermal processing. If ions are initially present, salt formation will take place during warm-up, i.e., the isolated ion pairs become part of a long range structure (Grim and Greenberg 1987). Therefore, comets may contain a salt component rather than the isolated ions or ion pairs of interstellar ice. E.g., above $\sim 240 \mathrm{~K}$, the formation of the $\mathrm{NH}_{4} \mathrm{OCN}$ salt in irradiated 
$\mathrm{H}_{2} \mathrm{O} / \mathrm{CO} / \mathrm{NH}_{3}$ samples is indicated by the appearance of a feature at $2215 \mathrm{~cm}^{-1}(4.511 \mu \mathrm{m}$; Grim and Greenberg 1987). Upon further warm-up, these salts sublime as neutrals (e.g., HOCN $\left.\& \mathrm{NH}_{3}\right)$.

$\mathrm{H}_{2} \mathrm{CO}$ could be an important component of interstellar ice (Tielens and Hagen 1982). Observations of solid $\mathrm{H}_{2} \mathrm{CO}$ were recently reported towards the protostellar source GL2136 (Schutte et al. 1996). Only a small barrier must be overcome to activate formaldehyde polymerization if $\mathrm{NH}_{3}$ is present. Possibly the excess energy could already be released if $\mathrm{H}_{2} \mathrm{CO}$ is produced by surface chemistry, i.e., hydrogenation of CO (Hiraoka et al. 1994). Otherwise, the analog experiments show that UV irradiation or some thermal annealing suffice for inducing polymerization. In comets, the nature of the polymers sensitively depends on the energy source (thermal annealing, UV) as well as the overall composition of the ice matrix (Table 1). Mixtures like those in table 1 are indicated both observationally and theoretically to be representative of interstellar and cometary ices, although the mixing ratio's will sensitively depend on the physical and chemical conditions at the time of condensation (Reviews Mumma et al. 1993, Schutte 1996). The mixing ratio will in turn strongly influence the relative abundances of the polymerization products (Table 1). Thus a precise chemical analysis of these compounds, as may be obtained by ROSETTA, will render important qualitative as well as quantitative information on the ambient conditions during the formation of the organic component of comets.

\section{REFERENCES}

Agarwal, V. K., W. A. Schutte, J. M. Greenberg, J. P. Ferris, R. Briggs, et al., Photochemical Reactions in Interstellar Grains, Photolysis of $\mathrm{CO}, \mathrm{NH}_{3}$, and $\mathrm{H}_{2} \mathrm{O}$, Origins of Life, 16, 21 (1985)

Bernstein, M. P., S. A. Sandford, L. J. Allamandola, S. Chang, M. A. Scharberg, Organic Components Produced by Photolysis of Realistic Interstellar and Cometary Ice Analogs Containing Methanol ApJ, 454, 327 (1995)

Briggs, R., G. Ertem, J. P. Ferris, J. M. Greenberg, P. J. McCain, C. X. Mendoza-Gomez, and W. Schutte, Comet Halley as an Aggregate of Interstellar Dust and Further Evidence for the Photochemical Formation of Organics in the Interstellar Medium, Origins of Life and Evolution of the Biosphere, 22, 287 (1992)

d'Hendecourt, L. B., and L. J. Allamandola, Time Dependent Chemistry in Dense Molecular Clouds. III. Infrared Band Cross Sections in Molecules in the Solid State at $10 \mathrm{~K}, A \& A S$, 64, 453 (1986)

Gerakines, P. A., W. A. Schutte, and P. A. Ehrenfreund, Ultraviolet Processing of Interstellar Ice Analogs. I. Pure Ices, $A \& A$, 312, 289 (1996)

Goldanskii, V. I., M. D. Frank-Kamenetskii, and I. M. Barkalov, Quantum Low-Temperature Limit of a Chemical reaction Rate, Science, 182, 1344 (1973)

Greenberg, J. M., What Are Comets Made Of? A Model Based on Interstellar Dust, in Comets, ed. L.L. Wilkening, University of Arizona press, Tucson, p. 131 (1982)

Grim, R. J. A., and J. M. Greenberg, Ions in Grain Mantles: The 4.62 Micron Feature by $\mathrm{OCN}^{-}$ in W33A, $A p J$, 321, L91 (1987)

Grim, R. J. A., J. M. Greenberg, M. S. de Groot, F. Baas, W. A. Schutte, B. Schmitt, Infrared Spectroscopy of Astrophysical Ices: New Insights in the Photochemistry, $A \& A S, 78,161$ 
(1989)

Hasegawa, T. I., E. Herbst, C. M. Leung, Models of Gas-Grain Chemistry in Dense Interstellar Clouds with Complex Organic Molecules, ApJS, 82, 167 (1992)

Hasegawa, T. I., E. Herbst, New Gas-Grain Chemical Models of Quiescent Dense Interstellar Clouds: The Effect of $\mathrm{H}_{2}$ Tunnelling Reactions and Cosmic Ray Induced Desorption, $M N$ $R A S, 261,83$ (1993)

Hiraoka, K., N. Ohashi, Y. Kihare, K. Yamamoto, T. Sato, A. Yamashita, Formation of Formaldehyde and Methanol from the Reactions of $\mathrm{H}$ Atoms with Solid CO at 10-20 K, Chemical Physics Letters, 229, 408 (1994)

Ito, K., H. J. Bernstein, The Vibrational Spectra of the Formate, Acetate, and Oxalate Ions, Canadian Journal of Chemistry, 34, 170 (1956)

Mumma, M. J., P. R. Weissman, and S. A. Stern, Comets and the Origin of the Solar System: Reading the Rosetta Stone, Protostars and Planets III, eds. E. H. Levy and J. I. Lunine, University of Arizona press, Tucson, p. 1177 (1993)

Ritzhaupt, G., J. P. Devlin, Ionic vs. Molecular Nature of Monomeric Ammonium and Hydronium Nitrate. Infrared Spectra of $\mathrm{H}_{3} \mathrm{O}^{+} \mathrm{NO}_{3}^{--}$and $\mathrm{NH}_{4}^{+} \mathrm{NO}_{3}^{--}$Solvated in Argon Matrices, Journal of Physical Chemistry, 81, 521 (1977)

Schutte, W. A. The Evolution of Interstellar Otganic Grain Mantles, PhD thesis, University of Leiden, Leiden (1988)

Schutte, W. A., L. J. Allamandola, S. A. Sandford, An Experimental Study of the Organic Molecules Produced in Cometary and Interstellar Ice Analogs by Thermal Formaldehyde Reactions, Icarus, 104, 118 (1993)

Schutte, W. A., P. A. Gerakines, T. R. Geballe, E. F. van Dishoeck, and J. M. Greenberg, Discovery of Solid Formaldehyde towards the Protostar GL 2136: Observations and Laboratory Simulation, $A \& A, 309,633$ (1996)

Schutte, W. A., and J. M. Greenberg, Further Evidence for the $\mathrm{OCN}^{-}$Assignment to the XCN Band in Interstellar Ice Analogs, A $6 A$ Letters, in press (1997)

Schutte, W. A., Formation and Evolution of Interstellar Icy Grain Mantles, The cosmic dust connection, ed. J. M. Greenberg, in press (1996)

Spaans, M., M. R. Hogerheijde, L. G. Mundy, E. F. van Dishoeck, Photon Heating of Envelopes around Young Stellar Objects: An Explanation for CO J =6-5 Emission, ApJ, 455, L167 (1995)

Tielens, A. G. G. M., and W. Hagen, Model Calculations of the Molecular Composition of Interstellar Grain Mantles, $A \& A, 114,245$ (1982)

Walker, J. F., Formaldehyde, third ed., Reinhold Publ. Co. (1964) 